\title{
A complexity scoring system for degenerative mitral valve repair
}

\author{
Anelechi C. Anyanwu, MD, Shinobu Itagaki, MD, Joanna Chikwe, MD, Ahmed El-Eshmawi, MD, and \\ David H. Adams, MD
}

\section{ABSTRACT}

Objective: To develop a score to allow stratification of complexity in degenerative mitral valve repair.

Methods: Retrospective modeling of data from 668 consecutive patients who underwent surgery for mitral valve prolapse. A complexity scoring scale was developed using a consensus approach, assigning a score to each valve, based on the following: prolapsing segments (weight 1 for each posterior segment; weight 2 for each anterior or commissural segment); presence of valve restriction (weight 2); presence of calcification (weight 3 if annulus involved, otherwise weight 2); and prior mitral valve repair (weight 3 ). Valve repairs were categorized into 3 groups based on the complexity score: 1 : Simple $(n=244) ; 2-4$ : Intermediate $(\mathrm{n}=260)$; $\geq 5$ : Complex $(\mathrm{n}=164)$.

Results: Mitral valve repair was successfully performed in 667 patients (repair rate: $99.9 \%$ ). The complexity score was directly correlated with surrogates of technical complexity. The mean cardiopulmonary bypass time increased with lesion complexity ([in minutes] simple: 152; intermediate: 167; complex 195; $P<.001)$. The median number of repair techniques utilized was related to lesion complexity (simple: 3 ; intermediate: 4 ; complex: 5 ; $P<.001$ ). Barlow's type etiology was more prevalent in complex cases $(63 \%)$, compared with simple $(9 \%)$ and intermediate $(35 \%)$ cases $(P<.001)$. Advanced repair techniques were required to complete repair in $51 \%$ of complex cases, compared with $14 \%$ of intermediate and $0 \%$ of simple cases $(P<.001)$. Early and late outcomes were similar.

Conclusions: Our scoring system may allow effective stratification of complexity of mitral valve repair. Future studies are required to evaluate the use of our score in a prospective setting. (J Thorac Cardiovasc Surg 2016;151:1661-70)

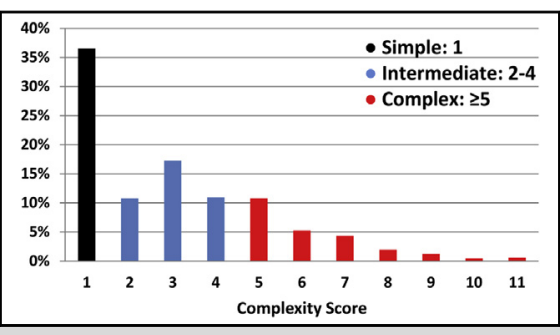

Mitral complexity scores. Score, 1 is Simple; 2 to 4 Intermediate; 5 or more Complex.

\section{Central Message}

We describe a basic scoring system that can be used to stratify complexity of mitral valve repair.

\section{Perspective}

Although mitral valve repair is recommended therapy for severe mitral regurgitation, the prevalence of valve replacement for degenerative disease remains relatively high. We describe a simple scoring system to grade the complexity of mitral valve repair. Based on a complexity score, surgeons and cardiologists can stratify valve repair complexity, allowing more-targeted surgical referral.

See Editorial Commentary page 1671.
Mitral valve repair is the recommended treatment for severe degenerative mitral valve regurgitation due to leaflet prolapse. ${ }^{1}$ Although almost all regurgitation due to prolapse has been well demonstrated to be repairable in expert hands, ${ }^{2-6}$ in practice, repair rates are very variable. ${ }^{7-9}$ Determining real-world repair rates for degenerative valves is difficult, as regional and national data sets do not have

\footnotetext{
From the Department of Cardiovascular Surgery, Icahn School of Medicine at Mount Sinai, New York, NY.

Read at the 95th Annual Meeting of The American Association for Thoracic Surgery, Seattle, Washington, April 25-29, 2015.

Received for publication May 25, 2015; revisions received Dec 30, 2015; accepted for publication Jan 9, 2016; available ahead of print Feb 28, 2016

Address for reprints: Anelechi C. Anyanwu, MD, Department of Cardiovascular Surgery, Mount Sinai Medical Center, 1190 Fifth Ave, New York, NY 10029 (E-mail: anelechi.anyanwu@mountsinai.org).

$0022-5223 / \$ 36.00$

Copyright $(2016$ by The American Association for Thoracic Surgery http://dx.doi.org/10.1016/j.jtcvs.2016.01.033
}

comprehensive data on etiology of disease, making differentiation of degenerative from nondegenerative etiologies impossible. Nevertheless, recent analysis of regional and national databases in the United States suggests that valve replacement is currently applied in approximately $40 \%$ of mitral valve procedures (for all comers), ${ }^{7-9}$ making degenerative valve replacement on a substantial scale likely.

The reasons for replacement of prolapsing valves vary, but the overriding factors seem to be surgeon inexperience or inexposure (as lower repair rates are systematically

Scanning this QR code will take you to the article title page. To view the AATS 2015 Webcast, see the URL at the end of the article. 
observed in surgeons and hospitals that have lower annual volumes of mitral valve repair ${ }^{7,8,10}$ ); varied commitment of surgeons and hospitals to mitral valve repair ${ }^{11}$; and the presence of complex valve pathology. ${ }^{12}$ This last factor is evident in published reports that show a lower rate of valve repair for bileaflet and anterior leaflet prolapse, compared with the rate for posterior leaflet prolapse. ${ }^{13-15}$ We have previously argued that the key to maximizing repair rates of mitral valve disease lies in differentiating among etiologies of valve disease and identifying the valve lesions preoperatively. ${ }^{16,17}$ Stratifying patients such that those who have complex etiologies or lesions are operated on by surgeons who handle a higher volume, or by surgeons well versed in complex valve repair, should yield higher repair rates, compared with nondirected patient referral. ${ }^{12}$ Although some groups have described precise outpatient planning of the surgical repair procedure based on thorough analysis of a preoperative transesophageal echocardiogram, ${ }^{18}$ this approach has not been widely adopted.

For many patients, therefore, the decision on complexity of repair often is made in the operating room, upon surgical valve analysis; at that point, if the surgeon is not experienced in the required repair techniques, then an unplanned valve replacement is undertaken. If, however, the complexity of valve repair can be easily predicted beforehand, then the likelihood of repair of a particular patient's valve by a specific surgeon could be determined a priori. The objective of this study is to develop a simple scoring system to grade the complexity of valve repair, and to evaluate the impact of complexity on operative processes and outcomes.

\section{METHODS \\ Study Design}

We retrospectively analyzed consecutive patients who underwent mitral valve surgery for degenerative mitral valve regurgitation, as performed by a single reference surgical team at Mount Sinai Medical Center (New York, NY) between 2003 and 2011. Each patient was assigned a complexity score, based on the weighed intraoperative anatomical characteristics, and a technique score, indicating the number of techniques used to complete the surgery. Patients were categorized into 3 groups based on the complexity score; comparisons were made in technique score and short- to mid-term outcomes.

Inclusion criteria for patients in the study were presence of mitral valve prolapse due to degenerative disease. Definitions of degenerative mitral valve disease have been described elsewhere. ${ }^{19}$ Patients who had prolapse due to other etiologies, such as rheumatic disease or endocarditis, were excluded, as were patients who had degenerative disease but did not have valve prolapse as a principal mechanism of regurgitation (such as degenerative mitral annular calcification causing central regurgitation). Patients who had concomitant aortic valve replacement were excluded.

Barlow's type disease was defined by the presence of a billowing distended valve requiring a large annuloplasty ring $^{20}$; although most patients with Barlow's type disease have multisegment prolapse, early forms of the disease, in which prolapse is limited to a single segment of the posterior leaflet (forme fruste), were included in the Barlow category.
Patients with a history of degenerative mitral valve repair were included, but only if they had presented with leaflet prolapse (other causes of recurrent regurgitation, such as annular dehiscence or leaflet restriction, were excluded). Patients with concomitant tricuspid annuloplasty, surgical ablation for atrial fibrillation, and coronary artery disease, which was found incidentally in preoperative catheterization, were included in the study. However, patients presenting with symptomatic coronary artery disease (and incidental mitral valve prolapse) were excluded. The research protocol was approved by the Icahn School of Medicine at Mount Sinai Institutional Review Board.

\section{Complexity and Technique Score}

The complexity score was developed, using a consensus approach, by the 2 senior authors (A.C.A. and D.H.A.). We selected key leaflet dysfunctions or lesions that could be identified easily on preoperative echocardiography and intraoperative valve analysis. The lesions or dysfunctions we decided on were as follows: presence or absence of prolapse in the 8 leaflet segments; restriction of any leaflet segment; calcification of the annulus; calcification of leaflets or subvalvular apparatus; and presence of prior repair (identifiable by history). We expected that these lesions and dysfunctions could be interrogated routinely using a good-quality echocardiographic study.

We arbitrarily assigned a weighting to each of these variables (Table 1). Weights were assigned as follows: posterior leaflet prolapse (score of 1 for each prolapsing segment $\mathrm{P} 1, \mathrm{P} 2, \mathrm{P} 3$; score of zero for nonprolapsing segments-multisegment prolapse is given the sum of scores for the prolapsing segments); anterior leaflet prolapse (score of 2 for each prolapsing segment A1, A2, A3; score of zero for nonprolapsing segments-multisegment prolapse is given the sum of scores for the prolapsing segments); commissural prolapse (score of 2 for each prolapsing commissure, anterolateral and posteromedial; score of zero for nonprolapsing commissures); calcification (score of 3 if calcification of the annulus (with or without leaflet or chordal calcification); score of 2 if calcification of papillary muscles, chordae or leaflets without annular calcification; score of zero if no calcification); leaflet restriction (score of 2 if present in any valve segment; score of zero if not present in any valve segment-multisegment restriction will get a single score of 2); and history of prior mitral valve repair (score of 3 ).

We used the cohort to further develop the scoring system. During each of these mitral valve repairs, we had prospectively recorded the lesions and dysfunctions for each valve. We retrospectively interrogated our database to allow scoring of each valve. Based on this information, we assigned a complexity score for each case, based on the following formula:

$$
\begin{aligned}
\text { Complexity score calculation }= & \text { redo } \cdot 3+\text { calc }(\cdot 3 \text { if annulus or } \\
& \cdot 2 \text { if leaflet or subvalvular }) \\
& + \text { leaflet_restriction } \cdot 2 \\
& +\mathrm{A} 1 \text { _prolapse } \cdot 2+\mathrm{A} 2 \text { _prolapse } \\
& \cdot 2+\mathrm{A} 3 \text { _prolapse } \cdot 2+\mathrm{P} 1 \text { _prolapse } \\
& \cdot 1+\mathrm{P} 2 \text { _prolapse } \cdot 1+\mathrm{P} 3 \text { _prolapse } \\
& \cdot 1+\mathrm{AC} \_ \text {lesion } \cdot 2+\mathrm{PC} \_ \text {lesion } \cdot 2,
\end{aligned}
$$

where redo $=$ prior mitral valve repair; calc $=$ calcification; A1, A2, A3, $\mathrm{P} 1, \mathrm{P} 2$, and $\mathrm{P} 3$ are segments of the mitral leaflets ${ }^{21}$; and $\mathrm{AC}$ and $\mathrm{PC}$ are anterior and posterior commissures.

For example, if a patient had an isolated P2 prolapse, with no leaflet restriction and no calcification, the complexity score would be 1 . If a patient had ruptured chordae to A2, with no other lesions or dysfunctions, the complexity score would be 2 . If a patient had Barlow's disease, with prolapse of $\mathrm{P} 2, \mathrm{P} 3, \mathrm{~A} 2$, and A3, in addition to restriction of P1 caused by a calcified papillary muscle, the complexity score would be 10 $(1+1+2+2+2+2)$.

Complexity scores were entered in a frequency chart. Based on examination of the distribution of complexity scores, we defined 3 
TABLE 1. Calculating the complexity score

\begin{tabular}{lc}
\hline \multicolumn{1}{c}{ Complexity variable } & Weight \\
\hline Segment prolapse & \\
P1 & 1 \\
P2 & 1 \\
P3 & 1 \\
A1 & 2 \\
A2 & 2 \\
A3 & 2 \\
Anterolateral commissure prolapse & 2 \\
Posteromedial commissure prolapse & 2 \\
Any leaflet restriction & 2 \\
Papillary muscle or leaflet calcification without & 2 \\
annular involvement & \\
Annular calcification & 3 \\
Previous mitral valve repair & 3 \\
\hline Complexity score $=$ sum of weights. Complexity strata (by complexity & score): \\
Simple: 1 ; Intermediate: $2-4$; Complex: $\geq 5$ &
\end{tabular}

Simple: 1; Intermediate: 2-4; Complex: $\geq 5$.

complexity groups: Simple (complexity score 1); Intermediate (complexity score 2-4); and Complex (complexity score $\geq 5$ ).

The technique score was calculated by adding the number of principal techniques we used to repair each valve. For example, if a patient had an annuloplasty, triangular resection and chordal transfer, 3 techniques were used to repair the valve. In contrast, if we performed a leaflet resection, sliding-plasty, artificial chordae implantation, annuloplasty, and commissural suture, then 5 techniques were used to repair the valve. We undertook valve repair using a lesion-based approach. The techniques included for calculation of the technique score were as follows: annuloplasty; anterior leaflet resection; posterior leaflet resection; sliding-plasty of posterior leaflet; posterior annular compression; commissuroplasty; chordal replacement with either artificial or native chords (multiplied by the number of segments resuspended by chords); leaflet cleft closure; techniques addressing calcium-decalcification, modified annuloplasty technique, and oversized-ring technique. Valve re-repair was counted as a separate technique, in addition to any of these techniques employed. When revision of the annuloplasty ring was required during re-repair, an additional score of 1 was added.

\section{Endpoints and Follow-up}

Successful repair was defined as less than mild mitral regurgitation at the postoperative echocardiogram, based on the grade defined by the guidelines of the American Society of Echocardiography. ${ }^{22}$ Operative mortality was defined as any death within 30 days, or at any time during the same hospital stay. Postoperative morbidity was defined as major adverse cardiac and cerebral events (stroke or myocardial infarction). The earliest echocardiogram on which moderate or greater mitral regurgitation was indicated was used to designate recurrent mitral regurgitation. Survival data were obtained for all patients; for documented US patients, this process was completed by cross-matching each patient's Social Security number with the Social Security Death Index. Median follow-up was 3.7 (range: 0.1 to 8.4 ) years.

\section{Statistical Analysis}

Continuous variables were reported as mean with standard deviation, or median with interquartile range. Categorical variables were expressed as a proportion. Assessment of differences in baseline characteristics and comorbidities among patients in each of the 3 complexity-score categories was performed using analysis of variance, with adjustment of multiple comparisons using the Bonferroni correction for normally distributed

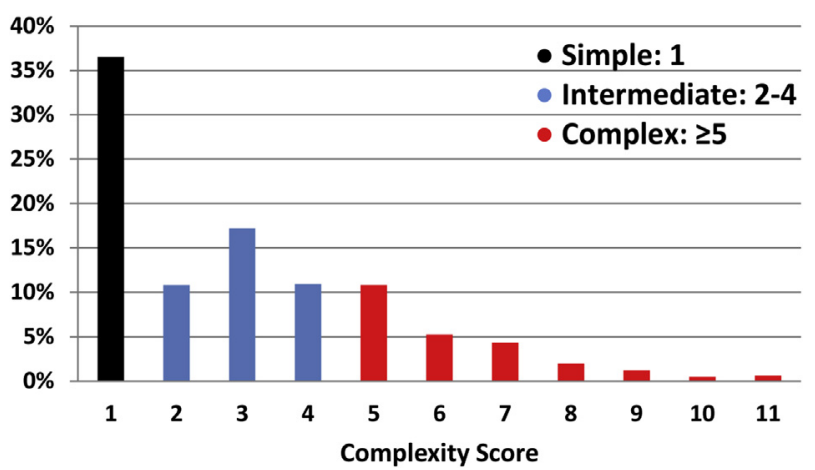

FIGURE 1. Distribution of complexity scores.

continuous variables, and Pearson's $\chi^{2}$ analysis for categorical variables. Survival and recurrent mitral regurgitation were analyzed using the Kaplan-Meier method and the log-rank test. Adjustments for multiple comparisons were made using the Sidak test. The impact of the complexity-score category on short- and mid-term outcomes was assessed by performing multivariate logistic regression and Cox proportional hazards regression. All tests were 2-tailed. All statistical analyses were performed using SAS, version 9.4 (SAS Institute, Cary, NC).

\section{RESULTS}

\section{Complexity Score and Patients Characteristics}

A total of 668 patients were identified. The median complexity score was 3 (interquartile range: 2-4). The distribution of complexity scores is displayed in Figure 1 . The contribution of complexity variables to the complexity score is summarized in Table 2 . Of the study population, 164 patients $(24 \%)$ were in the Complex group. The rest were distributed almost equally into the Simple (244 [37\%]) and Intermediate (260 [39\%]) groups.

Patient demographics and baseline comorbidities according to complexity are summarized in Table 3. As the complexity increased, patients tended to be younger and more often male, and to have a longer history of known mitral regurgitation-all features associated with Barlow's disease. Barlow's disease was most prevalent in the Complex group (63\% vs $9 \%$ for Simple and 35\% for Intermediate; $P<.001)$. The Simple group, by definition, consisted entirely of patients who had posterior leaflet prolapse, typically of the P2 scallop (230 of 244 [94.3\%]). Posterior leaflet prolapse was present in 225 of $260(87 \%)$ of Intermediate cases, of which 155 $(68 \%)$ involved $>1$ posterior leaflet segment, and in 152 of $164(93 \%)$ of Complex cases, of which $110(72 \%)$ involved multiple segments. Anterior leaflet prolapse was present in 60 of $260(23 \%)$ of the Intermediate group and 95 of $164(58 \%)$ of the Complex group. Commissural prolapse, leaflet calcification, annular calcification, leaflet restriction, and history of prior mitral valve repair were all significantly more prevalent in the Complex group (Table 2). 
TABLE 2. Breakdown of components of the complexity score by complexity group

\begin{tabular}{|c|c|c|c|c|}
\hline Variable & $\begin{array}{c}\text { Simple } \\
\text { (score: 1) } \\
(n=244) \\
\end{array}$ & $\begin{array}{c}\text { Intermediate } \\
\text { (score: } 2-4) \\
(n=260) \\
\end{array}$ & $\begin{array}{c}\text { Complex } \\
(\text { score: } \geq \mathbf{5}) \\
(\mathbf{n}=\mathbf{1 6 4}) \\
\end{array}$ & $\begin{array}{c}P \\
\text { value }\end{array}$ \\
\hline \multicolumn{5}{|l|}{ Prolapse } \\
\hline Any posterior leaflet & $244(100)$ & $225(86.6)$ & $152(92.7)$ & $<.001$ \\
\hline P1 segment & $2(0.8)$ & $99(38.1)$ & $89(54.3)$ & $<.001$ \\
\hline P2 segment & $230(94.3)$ & $214(82.3)$ & $144(87.8)$ & $<.001$ \\
\hline P3 segment & $12(4.9)$ & $135(51.9)$ & $110(67.1)$ & $<.001$ \\
\hline Any anterior leaflet & 0 & $60(23.1)$ & 95 (57.9) & $<.001$ \\
\hline A1 segment & 0 & $2(0.8)$ & $11(6.7)$ & $<.001$ \\
\hline A2 segment & 0 & $41(15.8)$ & $76(46.3)$ & $<.001$ \\
\hline A3 segment & 0 & $28(10.8)$ & $48(29.3)$ & $<.001$ \\
\hline $\begin{array}{l}\text { Anterolateral } \\
\text { commissure }\end{array}$ & 0 & $3(1.2)$ & $14(8.5)$ & $<.001$ \\
\hline $\begin{array}{r}\text { Posteromedial } \\
\text { commissure }\end{array}$ & 0 & $29(11.2)$ & $39(23.8)$ & $<.001$ \\
\hline Any leaflet restriction & 0 & $9(3.5)$ & $28(17.1)$ & $<.001$ \\
\hline $\begin{array}{l}\text { Papillary muscle or } \\
\text { leaflet calcification } \\
\text { without annular } \\
\text { involvement }\end{array}$ & 0 & $14(5.4)$ & $34(20.7)$ & $<.001$ \\
\hline Annular calcification & 0 & $21(8.1)$ & $44(26.8)$ & $<.001$ \\
\hline $\begin{array}{l}\text { Previous mitral valve } \\
\text { repair }\end{array}$ & 0 & $6(2.3)$ & $16(9.8)$ & $<.001$ \\
\hline
\end{tabular}

\section{Repair Feasibility and Short-Term Outcomes}

Surgical details and short-term outcomes are summarized in Table 4. Successful repair was achieved in all patients except one (667 of 668 [99.9\%]), so the repair rate was approximately $100 \%$ in all 3 complexity groups. The number of repair techniques used (technique score) was positively correlated with lesion complexity (Figure 2). Crossclamp time and cardiopulmonary bypass time increased with lesion complexity (respectively, 121 and 152 minutes in the Simple group; 128 and 167 minutes in the Intermediate group; and 155 and 195 minutes in the Complex group; both $P<.001)$. Requirement for a second

TABLE 3. Preoperative patient demographics and comorbidities

\begin{tabular}{|c|c|c|c|c|}
\hline Variable & $\begin{array}{c}\text { Simple } \\
(\mathrm{n}=\mathbf{2 4 4})\end{array}$ & $\begin{array}{c}\text { Intermediate } \\
\quad(n=\mathbf{2 6 0})\end{array}$ & $\begin{array}{r}\text { Complex } \\
(n=164)\end{array}$ & $\begin{array}{c}P \\
\text { value } \\
\end{array}$ \\
\hline Age (y) & $59.8 \pm 12.9$ & $56.0 \pm 13.8$ & $54.9 \pm 12.1$ & $<.001$ \\
\hline Female gender & $70(28.7)$ & $108(41.5)$ & $62(37.8)$ & .009 \\
\hline Ejection fraction $(\%)$ & $61.4 \pm 6.9$ & $59.7 \pm 8.4$ & $60.5 \pm 7.1$ & .035 \\
\hline Diabetes mellitus & $11(4.5)$ & $3(1.1)$ & $8(4.9)$ & .046 \\
\hline Coronary artery disease & $36(14.8)$ & $33(12.7)$ & $11(6.7)$ & .044 \\
\hline Renal failure & $2(0.8)$ & $0(0)$ & $0(0)$ & .18 \\
\hline Stroke & $5(2.1)$ & $6(2.3)$ & $6(3.7)$ & .57 \\
\hline $\begin{array}{l}\text { History of mitral } \\
\text { regurgitation (y) (only } \\
\text { if data available) }\end{array}$ & $13.3 \pm 14.4$ & $18.0 \pm 15.6$ & $21.5 \pm 15.9$ & $<.001$ \\
\hline
\end{tabular}

bypass run to address residual mitral regurgitation did not differ among the 3 groups (Simple, 2\%; Intermediate, $2.7 \%$; Complex, $4.9 \%$; $P=.24)$. No in-hospital mortality occurred in those who required a second bypass run. Freedom from residual mitral regurgitation, in-hospital major adverse cerebral and cardiovascular events, and 30-day mortality did not differ among the groups (Table 4).

\section{Complex Group}

The 164 patients in the Complex group had a median complexity score of 6 . The variables defining complexity varied, but all patients had $>1$ complexity-defining lesion or dysfunction, including the following: anterior leaflet prolapse (95 of $164[58 \%]$ ); posterior leaflet prolapse involving >1 segment (110[67\%]); involvement of one or both commissures (49 [30\%]); leaflet restriction $(28$ [17\%]); calcification of the leaflet or annulus (78 [48\%]); or prior repair $(16[10 \%])$. Multiple repair techniques were utilized, with a median of 5 per patient (interquartile range: 5-7). Advanced repair techniques, such as sliding-plasty, artificial chordae, commissuroplasty, and decalcification were used most frequently in the Complex group (compared with the Intermediate and Simple groups) (Table 5). Of the Complex group, $28(17 \%)$ had a complexity score of $\geq 8$; these patients had the longest bypass times (mean: 219 minutes) and required, on average, $\geq 7$ techniques to effect repair.

\section{Midterm Outcomes}

The 8-year survival of all study participants was $92.5 \% \pm 2.6 \%$ and did not differ among groups $(P=.82$; multiple comparison was not significant $)$. The 7-year freedom from greater-than-moderate mitral regurgitation and reoperation was $95.5 \% \pm 1.3 \%$ and $98.2 \% \pm 1.3 \%$, respectively, and did not differ among groups ( $P=.19$ and .40 , respectively; multiple comparison was not significant). A second bypass run was not associated with late mortality or recurrent mitral regurgitation or reoperation.

\section{DISCUSSION}

We have described a simple scoring system that differentiates mitral valve prolapse into 3 strata-simple, intermediate, and complex-based on the expected complexity of repair. We performed an internal validation of our scoring system by testing it on 668 mitral valve repairs performed in our institution. The scoring system seemed to have internal validity, as indicators of surgical complexity, such as cardiopulmonary bypass time, number of techniques used to repair the valve, and use of advanced repair techniques, were directly correlated with the complexity score. Although we derived the score based on data from intraoperative observation, all the components 
TABLE 4. Surgical details and short- to mid-term outcomes

\begin{tabular}{|c|c|c|c|c|}
\hline Variable & $\begin{array}{c}\text { Simple } \\
(\mathrm{n}=\mathbf{2 4 4})\end{array}$ & $\begin{array}{c}\text { Intermediate } \\
(\mathbf{n}=\mathbf{2 6 0})\end{array}$ & $\begin{array}{r}\text { Complex } \\
(n=164) \\
\end{array}$ & $P$ value \\
\hline \multicolumn{5}{|l|}{ Surgical details } \\
\hline Complexity score (IR) & 1.0 & $3(2-4)$ & $6(5-7)$ & $<.001$ \\
\hline Barlow's disease & $22(9.0)$ & $92(35.4)$ & $103(62.8)$ & $<.001$ \\
\hline Previous mitral valve repair & $0(0)$ & $6(2.3)$ & $16(9.8)$ & $<.001$ \\
\hline Successful repair & $244(100)$ & $260(100)$ & $163(99.4)$ & .21 \\
\hline Technique score (IR) & $3(3-4)$ & $4(3-5)$ & $5(5-7)$ & $<.001$ \\
\hline Back on bypass & $5(2.0)$ & $7(2.7)$ & $8(4.9)$ & .24 \\
\hline Crossclamp time (min) & $121 \pm 41$ & $128 \pm 49$ & $155 \pm 51$ & $<.001$ \\
\hline Cardiopulmonary bypass time (min) & $152 \pm 45$ & $167 \pm 56$ & $195 \pm 55$ & $<.001$ \\
\hline \multicolumn{5}{|l|}{ Concomitant surgery } \\
\hline Coronary artery bypass grafting & $31(12.7)$ & $23(8.9)$ & $7(4.3)$ & .015 \\
\hline Maze procedure & $37(15.2)$ & $60(23.1)$ & $33(20.1)$ & .079 \\
\hline Tricuspid annuloplasty & $158(64.8)$ & $174(66.9)$ & $104(63.4)$ & .74 \\
\hline \multicolumn{5}{|l|}{ Short- and mid-term outcomes } \\
\hline In-hospital major adverse cerebral and cardiovascular events & $2(0.8)$ & $7(2.7)$ & $1(0.6)$ & .13 \\
\hline 30-d mortality & $1(0.4)$ & $2(0.8)$ & $1(0.6)$ & .87 \\
\hline Freedom from more-than-moderate mitral regurgitation at 7 years $(\%)$ & $92.7 \pm 2.6$ & $96.5 \pm 1.8$ & $98.4 \pm 1.6$ & .19 \\
\hline Freedom from reoperation at 7 years $(\%)$ & $97.5 \pm 1.5$ & $98.3 \pm 1.2$ & 100 & .40 \\
\hline Survival at 8 years $(\%)$ & $95.7 \pm 1.8$ & $88.3 \pm 5.6$ & $92.6 \pm 7.4$ & .82 \\
\hline
\end{tabular}

Values are $\mathrm{n}(\%)$, or mean \pm standard deviation, unless otherwise indicated. $I R$, Interquartile range.

of the score can be evaluated in prospective fashion, using preoperative echocardiography and patient history.

Although repairs on valves for those in the Complex group took longer and were more technically demanding (compared with the Simple and Intermediate groups), we were able to repair all the valves in this group, and early and midterm outcomes were similar to those of patients in the Simple and Intermediate groups. Performance of a long or complicated repair did not seem to compromise other objectives of surgery. The rates of tricuspid valve repair and ablation for atrial fibrillation were similar in all groups. Although the incidence of concurrent coronary artery bypass surgery was lower in the Complex group, we believe the reason was the lower incidence of coronary artery disease and the younger age in the Complex group (Barlow's disease, which was the dominant etiology in the

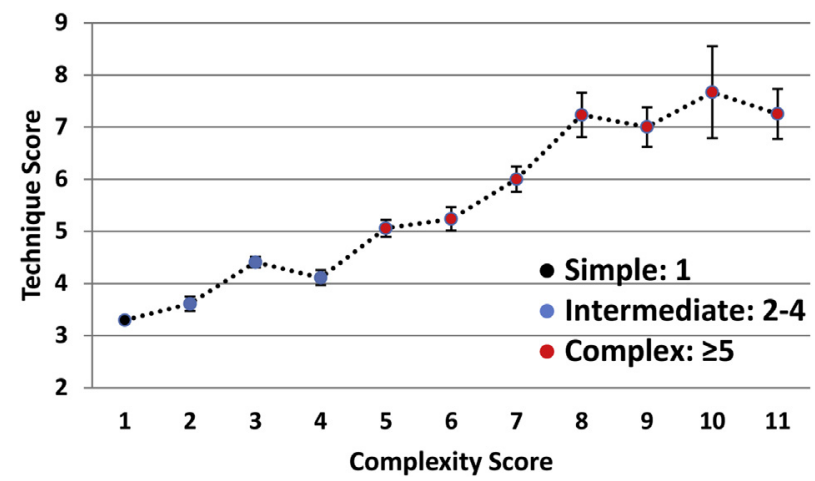

FIGURE 2. Technique scores (mean and standard error [bars]) according to complexity score.
Complex group, typically affects younger patients ${ }^{19}$ ). Our data, therefore, show that in a high-volume reference center, the results of valve repair are excellent, regardless of needing extended time or technical input to achieve complex repair.

\section{Current Practice of Mitral Valve Repair}

The current American Heart Association/American College of Cardiology Guidelines recommend mitral valve repair as the treatment of choice for mitral valve regurgitation. ${ }^{1}$ These guidelines recommend that mitral valve replacement not be undertaken for posterior leaflet prolapse involving less than half of the leaflet, unless repair has been attempted and failed. No similar recommendation is made for the anterior leaflet or for posterior leaflet prolapse that involves more than half the leaflet. These recommendations, based on best available evidence and consensus, are an acknowledgement of the following points: (1) Anterior leaflet repair is more difficult than posterior leaflet repair; (2) Posterior leaflet repair of multiple segments is more difficult than that of a single-segment prolapse; and (3) Some degenerative valves are replaced with no prior attempt at repair. The guidelines additionally recommend that surgery for asymptomatic patients who do not have ventricular dysfunction or dilation should be performed in "centers of excellence." These recommendations reflect recognition that, as mitral valve prolapse progresses beyond a single segment of the posterior leaflet, it requires increasing technical skill, experience, and expertise to achieve successful repair. As mentioned, historical studies 
TABLE 5. Details of repair techniques by complexity group

\begin{tabular}{|c|c|c|c|c|}
\hline Variable & $\begin{array}{c}\text { Simple } \\
(\mathrm{n}=\mathbf{2 4 4})\end{array}$ & $\begin{array}{c}\text { Intermediate } \\
(\mathbf{n}=\mathbf{2 6 0})\end{array}$ & $\begin{array}{r}\text { Complex } \\
(n=164) \\
\end{array}$ & $\begin{array}{c}P \\
\text { value }\end{array}$ \\
\hline $\begin{array}{l}\text { Technique score } \\
\quad \text { (interquartile range) }\end{array}$ & $3(3-4)$ & $4(3-5)$ & $5(5-7)$ & $<.001$ \\
\hline Annuloplasty & $244(100)$ & 259 (99.6) & $160(98.2)$ & .053 \\
\hline $\begin{array}{l}\text { Posterior leaflet } \\
\text { resection }\end{array}$ & $233(95.5)$ & 207 (79.6) & $136(82.9)$ & $<.001$ \\
\hline Sliding plasty & $75(30.7)$ & $147(56.5)$ & $103(62.8)$ & $<.001$ \\
\hline Compression sutures & $107(43.9)$ & $114(43.9)$ & $90(54.9)$ & .049 \\
\hline $\begin{array}{l}\text { Anterior leaflet } \\
\text { resection }\end{array}$ & $0(0)$ & $5(1.9)$ & $12(7.3)$ & $<.001$ \\
\hline Chordal replacement & $62(25.4)$ & $121(46.5)$ & $117(71.3)$ & $<.001$ \\
\hline 1-segment support & $62(25.4)$ & $91(35.0)$ & $65(39.6)$ & $<.001$ \\
\hline$>1$-segment support & $0(0)$ & $30(11.5)$ & $52(31.7)$ & $<.001$ \\
\hline \multicolumn{5}{|l|}{ Gap closure } \\
\hline Between P1 and P2 & $45(18.4)$ & $30(11.5)$ & 24 (14.6) & .093 \\
\hline Between P2 and P3 & $28(11.5)$ & $53(20.4)$ & $41(25.0)$ & .001 \\
\hline \multicolumn{5}{|l|}{ Commissural plasty } \\
\hline Anterolateral & $2(0.8)$ & $9(3.5)$ & $30(18.3)$ & $<.001$ \\
\hline Posteromedial & $8(3.3)$ & 49 (18.9) & $55(33.5)$ & $<.001$ \\
\hline Decalcification & 0 & $13(5.0)$ & $27(16.5)$ & $<.001$ \\
\hline $\begin{array}{l}\text { Modified pledgeted } \\
\text { annular suture } \\
\text { technique }\end{array}$ & 0 & $9(3.5)$ & $13(7.9)$ & $<.001$ \\
\hline $\begin{array}{l}\text { Oversized annuloplasty } \\
\text { technique }\end{array}$ & 0 & $4(1.5)$ & $11(6.7)$ & $<.001$ \\
\hline $\begin{array}{l}\text { Previous mitral valve } \\
\text { repair }\end{array}$ & 0 & $6(2.3)$ & $16(9.8)$ & $<.001$ \\
\hline $\begin{array}{l}\text { Removal of old } \\
\text { annuloplasty ring }\end{array}$ & 0 & $6(2.3)$ & $12(7.3)$ & $<.001$ \\
\hline
\end{tabular}

Values are n (\%) unless otherwise indicated.

have shown progressively higher valve replacement rates as disease complexity increases. ${ }^{13-15,23}$

The reasons surgeons replace reparable valves are multifactorial; to understand these requires appreciation of the unique factors involved in the training, learning, professional development, evolution, and practice of a mitral valve surgeon. ${ }^{24}$ The hesitancy of many surgeons to repair bileaflet, anterior leaflet, or multiple-segment posterior leaflet prolapse, and valves with restriction, calcification, or prior repair, likely stems from concerns about failure (inability to predictably execute a technically adequate repair), durability, and the prolonged bypass time required to do a complex valve repair. As the culpability for early operative failure is often ascribed to the operating surgeon, many surgeons faced with a complex valve opt for the relative "safety" of a mitral valve replacement, rather than risk being blamed for early failure of a valve repair. ${ }^{24}$

We have demonstrated in this study that the long-bypass runs for complex valve repairs do not significantly compromise outcomes: The valves are almost always reparable, and the repairs seem durable in the midterm. Another recent series from a reference center corroborates our findings, performing only 5 replacements in a series of 525 patients, ${ }^{4}$ confirming that almost all valves are reparable regardless of complexity. Although a nearly $100 \%$ repair rate for all comers can be predictably achieved only in a reference center, some valves, such as those in our Simple category, clearly do not require specific subspecialist expertise to predictably repair. We have previously suggested that such valves can be predictably repaired by a general cardiac surgeon who has an interest in mitral valve repair, and do not require selective referral to centers of excellence (reference centers). ${ }^{16}$ However, some complex valves undoubtedly require a mitral valve subspecialist in a reference center to achieve a durable repair reproducibly. ${ }^{16,17,25,26}$ We have previously suggested that differentiation of etiology into Barlow's disease and fibroelastic deficiency is the key factor to stratifying complexity, ${ }^{17,19}$ but the spectrum of pathology varies widely, such that many valves cannot be so simply categorized. Therefore, although complex valves have been recognized as being harder to repair, and are more likely to get replaced if treated by nonspecialized or low-volume mitral surgeons, no simple means has been available previously to prospectively identify these patients.

\section{Possible Implications of Our Complexity Score}

Our approach to stratification can be helpful on various levels. A cardiologist faced with a patient who has severe regurgitation due to mitral valve prolapse can, based on the echocardiogram, put the patient into the simple, intermediate, or complex category; decisions can then be made on the most-appropriate referral pathway. For example, a patient who has simple pathology, isolated P2 prolapse, can be referred to an institutional surgeon who performs 10 degenerative valve repairs a year, and reasonably can be expected to come out of surgery with a good durable repair. On the other hand, faced with a patient who has a complex score, a cardiologist would know that a replacement is more likely in the hands of a low-volume institutional surgeon, and may consider instead a referral to a local or regional center of excellence. For a surgeon to whom a case of mitral valve prolapse is referred, the stratification is helpful in predicting reparability. For example, our analysis shows that ability to perform several techniques, including sliding leaflet plasty, chordal replacement, commissuroplasty, cleft closure, and repair of multisegment prolapse, is critical to effecting repairs in intermediate-complexity cases. If a surgeon is faced with a case of intermediate-complexity regurgitation and is not comfortable in application of these techniques, the probability of a successful and durable repair is not high. Such a case may be better referred to colleagues who have intermediate-level techniques in their surgical armamentarium. 
The complex cases require the greatest consideration. Repair of such valves requires a commitment to the longer time and more-extensive technical steps required to achieve a repair. Our data show that in $51 \%$ of complex cases (compared with $14 \%$ of intermediate cases, and none of the simple cases) $\geq 1$ advanced surgical technique was necessary to execute repairs. These advanced techniques, in our practice, included the following: decalcification; modified annuloplasty (to accommodate calcification or valve asymmetry); valve rerepair; and sliding leaflet plasty combined with chordal support of multiple segments. (Other advanced techniques that we have not studied explicitly, such as multiple chordal replacement to all leaflet segments and papillary muscle repositioning may be used for complex repairs). We believe that with prospective classification of cases, the global repair rates for mitral valve disease would improve substantially, as patients can be better matched to surgeons who are most likely to accomplish a repair.

Additionally, our stratification can be applied for development of local expertise. For many patients, travelling to reference centers for surgery is well acknowledged to not be a logistically practical option. Even greater barriers in many settings to routine referral of patients to outside institutions are various local, institutional, individual, financial, and other factors. ${ }^{24}$ Development of local expertise in mitral valve surgery should therefore be a priority in all major health systems. Identification of complex and intermediate cases, and restricting these to a designated surgeon in a center or locality (who is willing to develop an interest in complex mitral valve repair), likely will result in a progressive increase in repair rates, as a result of concentrated exposure to complex cases. However, the alternative norm, ie, referring patients who have complex disease to multiple surgeons (who in most cases will replace those valves) will maintain the low repair rate for complex pathology in the locality.

For the expert surgeon, stratifying complexity is less relevant (because the vast majority of valves likely will be repaired regardless of complexity), but applications of our scoring system are still potentially viable, such as identification of training cases, prediction of operative times and planning of myocardial protection strategy, and audit and quality control. Our cardiopulmonary bypass times are longer than those seen in some contemporary series, ${ }^{3,4}$ which may reflect partly our strong educational and training bias, a commitment to durable repair in all cases, and our frequent application of tricuspid annuloplasty; therefore, our study can not predict operative times in other institutions, as this depends on surgeon and institutional practice. Finally, stratification of case complexity can help in clinical research by allowing better interpretation and comparison of studies, and by defining homogenous populations for testing of new techniques and technologies.

\section{Limitations and Strengths}

The strengths of this study include the following: the relatively large number of patients who underwent operation in the same era; heterogeneity of complexity with inclusion of $>200$ patients with Barlow's disease; surgeries performed by a single-reference surgical team committed to attempting valve repair in all cases of degenerative prolapse; and a very high repair rate that avoids exclusion of patients who have advanced valve disease and allows for inclusion of all forms of complex repair. Although we validated this study internally, no external validation was done. We therefore cannot be certain that this score will have similar meanings in other centers and settings-further study is required to confirm generalizability.

Our near- $100 \%$ repair rate is, paradoxically, a limitation of our study, because it cannot allow predictability of repair rates in centers with lower repair rates, particularly in the non-reference center setting. In addition, because repair surgeons vary in their approach, our methods may not be generalizable to other surgeons using different repair strategies. However, although the numerical weightings may vary in different centers, we believe that the rankings of simple, intermediate, and complex, as defined here, still will apply to most, if not all, cohorts involving degenerative disease, because most direct and indirect data indicate that incremental lesions and dysfunctions do increase the complexity of valve repair.

Our arbitrary approach to assigning weighting for the scoring system is another limitation of our study. A review of the literature, however, did not yield any studies on the complexity of valve repair with regression analysis that could have assigned objective weightings, so our only approach was to use subjective weightings. Variable selection and weighting was undertaken by 2 of the authors only, and our perception of complexity might differ from that of other surgeons and cardiologists. A wider panel of experts might have identified other factors or assigned other weightings. Our analysis, however, demonstrated good discriminatory ability of the scoring system, suggesting that our arbitrary weighting was at least partly correlated with disease complexity. A larger data set with prospectively collected valve-analysis data would allow objective weighting of variables; however, to our knowledge, no such data sets are currently available. Finally, our score was derived from intraoperative assessment, but we are recommending its utilization based on preoperative echocardiography. Further study is needed to evaluate performance of the score when it is applied with echocardiography in a prospective, preoperative setting. 


\section{CONCLUSIONS}

We have described a simple approach to stratifying degenerative mitral valve prolapse according to the expected complexity of valve repair. Further study is required to validate our score in other settings and to evaluate practical applications of our model.

\section{Conflict of Interest Statement}

The Icahn School of Medicine at Mount Sinai receives royalty payments from Edwards Lifesciences (Irvine, Calif) and Medtronic (Minneapolis, Minn) for intellectual property related to Dr Adams' involvement in the development of 2 mitral and 1 tricuspid valve repair rings. Dr Adams is the National Co-Principal Investigator of the CoreValve United States Pivotal Trial, which is supported by Medtronic. None of the sponsoring organizations had any role in the design or conduct of the study; collection, management, analysis, and interpretation of the data; preparation, review, or approval of the manuscript; or decision to submit the manuscript for publication. All other authors have nothing to disclose with regard to commercial support.

You can watch a Webcast of this AATS meeting presentation by going to: http://webcast.aats.org/2015/Video/ Monday/04-27-15_4E_1535_Anyanwu.mp4.

\section{References}

1. Nishimura RA, Otto CM, Bonow RO, Carabello BA, Erwin JP III, Guyton RA, et al. 2014 AHA/ACC guideline for the management of patients with valvular heart disease: a report of the American College of Cardiology/American Heart Association Task Force on Practice Guidelines. J Am Coll Cardiol. 2014;63: e57-185.

2. Castillo JG, Anyanwu AC, Fuster V, Adams DH. A near 100\% repair rate for mitral valve prolapse is achievable in a reference center: implications for future guidelines. J Thorac Cardiovasc Surg. 2012;144:308-12.

3. David TE, David CM, Manlhiot C. Simplici-t annuloplasty band for mitral valve repair for degenerative disease. Ann Thorac Surg. 2014;98:1551-6.

4. Goldstone AB, Cohen JE, Howard JL, Edwards BB, Acker AL, Hiesinger W, et al. A "repair-all" strategy for degenerative mitral valve disease safely minimizes unnecessary replacement. Ann Thorac Surg. 2015;99:1983-90; discussion 1990-1.

5. Suri RM, Burkhart HM, Daly RC, Dearani JA, Park SJ, Sundt TM III, et al. Robotic mitral valve repair for all prolapse subsets using techniques identical to open valvuloplasty: establishing the benchmark against which percutaneous interventions should be judged. J Thorac Cardiovasc Surg. 2011; 142:970-9.

6. Mihaljevic T, Jarrett CM, Gillinov AM, Williams SJ, DeVilliers PA, Stewart WJ, et al. Robotic repair of posterior mitral valve prolapse versus conventional approaches: potential realized. J Thorac Cardiovasc Surg. 2011;141:72-80. e71-4.

7. Vassileva CM, McNeely C, Spertus J, Markwell S, Hazelrigg S. Hospital volume, mitral repair rates, and mortality in mitral valve surgery in the elderly: an analysis of US hospitals treating medicare fee-for-service patients. J Thorac Cardiovasc Surg. 2015;149:762-8.e1.

8. LaPar DJ, Ailawadi G, Isbell JM, Crosby IK, Kern JA, Rich JB, et al. Mitral valve repair rates correlate with surgeon and institutional experience. J Thorac Cardiovasc Surg. 2014;148:995-1003; discussion 1003-4.

9. Chatterjee S, Rankin JS, Gammie JS, Sheng S, O'Brien SM, Brennan JM, et al. Isolated mitral valve surgery risk in 77,836 patients from the society of thoracic surgeons database. Ann Thorac Surg. 2013;96:1587-94; discussion 1594-5.

10. Bolling SF, Li S, O’Brien SM, Brennan JM, Prager RL, Gammie JS. Predictors of mitral valve repair: clinical and surgeon factors. Ann Thorac Surg. 2010;90: 1904-11; discussion 1912.

11. Anyanwu AC, Bridgewater B, Adams DH. The lottery of mitral valve repair surgery. Heart. 2010;96:1964-7.

12. Adams DH, Rosenhek R, Falk V. Degenerative mitral valve regurgitation: best practice revolution. Eur Heart J. 2010;31:1958-66.

13. Petracek MR, Leacche M, Solenkova N, Umakanthan R, Ahmad RM, Ball SK, et al. Minimally invasive mitral valve surgery expands the surgical options for high-risk patients. Ann Surg. 2011;254:606-11.

14. Seeburger J, Borger MA, Doll N, Walther T, Passage J, Falk V, et al. Comparison of outcomes of minimally invasive mitral valve surgery for posterior, anterior and bileaflet prolapse. Eur J Cardiothorac Surg. 2009;36:532-8.

15. Suri RM, Schaff HV, Dearani JA, Sundt TM III, Daly RC, Mullany CJ, et al. Survival advantage and improved durability of mitral repair for leaflet prolapse subsets in the current era. Ann Thorac Surg. 2006;82:819-26.

16. Adams DH, Anyanwu AC. The cardiologist's role in increasing the rate of mitral valve repair in degenerative disease. Curr Opin Cardiol. 2008;23:105-10.

17. Adams DH, Anyanwu AC. Seeking a higher standard for degenerative mitral valve repair: Begin with etiology. J Thorac Cardiovasc Surg. 2008;136: $551-6$.

18. Drake DH, Zimmerman KG, Hepner AM, Nichols CD. Echo-guided mitral repair. Circ Cardiovasc Imaging. 2014;7:132-41.

19. Anyanwu AC, Adams DH. Etiologic classification of degenerative mitral valve disease: Barlow's disease and fibroelastic deficiency. Semin Thorac Cardiovasc Surg. 2007;19:90-6.

20. Adams DH, Anyanwu AC, Rahmanian PB, Abascal V, Salzberg SP, Filsoufi F. Large annuloplasty rings facilitate mitral valve repair in Barlow's disease. Ann Thorac Surg. 2006;82:2096-100; discussion 2101.

21. Carpentier A. Cardiac valve surgery-the "French correction" J Thorac Cardiovasc Surg. 1983;86:323-37.

22. Zoghbi WA, Enriquez-Sarano M, Foster E, Grayburn PA, Kraft CD, Levine RA, et al. Recommendations for evaluation of the severity of native valvular regurgitation with two-dimensional and Doppler echocardiography. J Am Soc Echocardiogr. 2003;16:777-802.

23. Mohty D, Orszulak TA, Schaff HV, Avierinos JF, Tajik JA, Enriquez-Sarano M Very long-term survival and durability of mitral valve repair for mitral valve prolapse. Circulation. 2001;104(12 Suppl 1):I1-7.

24. Frater RW. Assumptions and realities of mitral valve repair. J Heart Valve Dis. 2003; 12:11-3.

25. McCarthy PM. When is your surgeon good enough? When do you need a "referent surgeon"? Curr Cardiol Rep. 2009;11:107-13.

26. Bridgewater B, Hooper T, Munsch C, Hunter S, von Oppell U, Livesey S, et al. Mitral repair best practice: proposed standards. Heart. 2006;92:939-44.

\section{Discussion}

Dr Y. Joseph Woo (Stanford, Calif). I congratulate you and your colleagues on designing a thoughtful, systematic scoring and categorization system for mitral valve prolapse pathology. As the SYNTAX (Synergy Between PCI With Taxus and Cardiac Surgery) score for percutaneous coronary intervention, the right ventricular failure scores for left ventricular assist device, and numerous other scoring systems in medicine and surgery, have guided clinical decision making, the time is right for the advancement of a scoring system for mitral valve degenerative pathology, which can inform us regarding both complexity and, potentially, reparability. This is particularly pertinent as the 2014 American College of Cardiology/American Heart Association guidelines give a $2 \mathrm{~A}$ recommendation for intervention on asymptomatic 
severe mitral regurgitation with preserved left ventricular size and function, provided the center-of-excellence repair rate exceeds $95 \%$, and with a $<1 \%$ mortality.

I have a few questions. In this initial version, you utilized intraoperative findings for your scoring system. Could you please elaborate more upon how you will transition from this to scoring based purely upon preoperative imaging, and thus be able to impact operative planning or perhaps patient referral to a specialized center, as herein lies the greatest potential clinical impact of this score?

Dr Anelechi C. Anyanwu (New York, NY). The next step for us is to do a trial in our echocardiography laboratory and develop a system that we could use to score every valve at the time of echocardiography, based on these factors, and see how that will add to the predictability of the model.

Dr Woo. Your scoring system was closely correlated with bypass time, number of repair techniques, and use of advanced techniques. However, your event rate of only one repair failure in 668 does pose a challenge in validating your scoring system in terms of its ability to predict repair failure. Have you been able to identify another data set, either at your institution or elsewhere, that has a higher event rate, to which you could apply your scoring system to examine the correlation with failure of repair?

Dr Anyanwu. Well, the aim of the system is not to predict repair rates, because, as your group, and ours, and others have shown, almost every degenerative valve can be repaired. So the repair rate should approximate $100 \%$. But the reality is that the repair rate varies depending on the setting in which the patient has the repair.

So basically, if you have a simple valve and you go to a surgeon who does 10 valve repairs a year, you should have a $95 \%$ repair probability. If you have an intermediate valve, you probably go to a surgeon who is doing 20 a year; you should still have a $95 \%$ repair probability. If you have a complex valve, and you go to a reference surgeon, then you should have a $100 \%$ repair rate.

Dr Woo. In your paper, you described advanced techniques as including decalcification, re-repair, papillary muscle repositioning, and sliding leaflet plasty with chordal support of multiple segments. Because these were utilized in about $14 \%$ of your intermediate lesions, and $50 \%$ of complex lesions, you surmise that without these techniques the repair rates could have been as low as $86 \%$ and $50 \%$, respectively.

Recognizing that a conditional inverse is not always necessarily true, and that in your hands or those of others, the use of additional standard techniques might have yielded an excellent repair rate, could you possibly speculate as to what a more realistic repair rate for intermediate and complex groups would have been, had one exhausted all of the standard repair techniques and not utilized any of the advanced techniques?
Dr Anyanwu. I think mitral valve repair is a continuum; you do not just get comfortable with a particular repair rate and then stay there. The aim of this kind of stratification would be for the surgeon doing intermediate techniques to do more and more of them. So if you have an intermediate case, your colleague could give that one to you.

So you might start at a $70 \%$ repair rate with standard techniques. Then for the next patient, you do a sliding plasty and it might work; for the next patient, you do a decalcification and it might work. You will evolve over time, and repair even more valves. The idea is to consolidate the exposure to intermediate- and high-risk cases in such a way as to allow professional development of local expertise.

Dr Woo. This study spans a 9-year timeframe, during which the repair techniques at your center have both expanded and evolved-for example, more recently they have focused on targeted resections. Might you elaborate upon whether and how the evolution of repair techniques has impacted the correlation of your scoring system?

Dr Anyanwu. I think the repair techniques themselves might have evolved, but the number of techniques used is still the same. If we did a quadrangular resection for a patient in the past, and we now do a polytetrafluoroethylene chord, or we did a triangular resection, it still counts as one technique. It is rare that you will substitute a simple technique for a complex one. So, for example, instead of doing a sliding plasty, you might do a multiple polytetrafluoroethylene chordae, which is still complex. So the techniques themselves have evolved, but the key variable, which is the number of techniques, or techniques the surgeon needs to fix the valve, has been relatively static in the time period.

Dr Woo. Thank you again for an outstanding body of work and for continuing to lead the thought process on advancing and perfecting mitral valve repair surgery.

Dr Anyanwu. Thanks.

Dr Francis C. Wells (Cambridge, United Kingdom). I rise to congratulate you and your group on another innovative contribution to the management of mitral regurgitation patients. The point I would like to ask you, Anelechi, is would you feel comfortable with this process now if it could be standardized across multiple centers. I think that must be the next step. Perhaps third-party payers may use this information to refer patients from institutions of lower experience to those of higher excellence, similar to what happened in the lung volume reduction surgery trials? Second, if that did not happen (patients being referred to centers of excellence), because you know what difficulty we have in getting patients into specialty centers, and the massive variability in repair rates across the country, would we feel comfortable with the higher-scoring group, particularly in the elderly group of patients, having valve insertion, with complete subvalvar preservation discussed with them upfront, rather than the potential for a failed repair? 
Dr Anyanwu. I think we have to accept that not every patient can travel for surgery, and that is not what we are suggesting should happen. What should happen is consolidation of local expertise. So if patients cannot travel, what we need is to utilize the local expertise. So even if the repair rate is low in a given hospital, if all the patients are going to a particular surgeon in that hospital, the repair rate will rise over time.

And I agree with you - when it comes to the very complex valves, a surgeon who is not an expert, well versed in advanced techniques, is not going to repair that valve. So for such patients, if they cannot travel, then I agree, they should be told upfront that they are going to have a valve replacement as opposed to an attempted repair.

Dr Pasquale Totaro (Palermo, Italy). First, congratulations on your outstanding results. You showed in your abstract that patients with complex lesions and complex repairs had even better results in terms of freedom from mitral regurgitation, compared to patients with simpler repairs. I have 2 questions related to this finding.

You did not mention in your presentation the surgeon variable. Is it possible that the majority of the simple repairs were made by the trainee, as opposed to the more-complex operations? The second question is: Could we speculate that in approaching a complex valve lesion, the surgeon must pay more attention to the mechanism and the etiology, and so the final result is that the repair that is needed is surely more complex, but also more definite, compared to a case with a simple lesion? Thank you.

Dr Anyanwu. Regarding the issue of the surgeon variable, the operations were all done by the same team in a reproducible manner. So I do not think that is a factor.
As to why the complex repairs might have been more stable, it is all tied down to the etiology, because if you look at the etiology of complex valve pathologies, either Barlow's disease or valve re-repair, Barlow's disease often requires multiple-segment stabilization, and it is possible that the long-term outcomes are more stable. Patients who have isolated P2 prolapse can still have failures that are due to progression of native disease because they have ruptured a chord to the anterior leaflet, and they may come back with recurrent regurgitation. So I think the differentiation in long-term stability of repair has more to do with the etiology than with the techniques of repair.

Dr Andrea Colli (Padua, Italy). I just would like to say congratulations on the paper and to make a brief comment. You probably know that we in Padua started a program with transapical off-pump mitral valve repair with neochord implantation, and we have done some classification similar to yours, to predict the reparability of our valves and the durability of our repairs. What we have seen that is different from your findings is that in the simplest cases, the better results we have seen are in only isolated $\mathrm{P} 2$ prolapse. So one thing that might be very useful is to compare your series with ours, or with the classification that we made, to predict which patients could be safely treated with the transapical off-pump mitral valve repair procedure.

Dr Anyanwu. We are looking at 8-year follow-up. That is what we base our durability on. I do not think you have 8 -year follow-up yet with your neochordae. So you do not know yet how durable those repairs are. You have just very limited, short-term data.

Dr Colli. Yes, that is definitely true-we do not have your follow-up. 